\title{
The Impact of Human Behavior on Dolphin's Life in the Dolphin Tale Series (2011 \& 2014)
}

\author{
Azizah, Kuni Maskurotal ${ }^{1}$; Sudja'ie, Mimien Aminah2; Februansyah, Rizki ${ }^{3}$ \\ English Department, Faculty of Humanities, Jenderal Soedirman University \\ kunimaskurotul.aziza@gmail.com, mimien.aminah@unsoed.ac.id ${ }^{2}$, \\ rizki.februansyah@unsoed.ac.id ${ }^{3}$
}

\begin{abstract}
Article History:
First Received:

$28 / 05 / 2020$

Final Revision:

$18 / 12 / 2020$

Available online:

$30 / 12 / 2020$

Abstract. This research aims to figure out how human's behaviors affect the dolphin's life in Dolphin Tale. The researcher used qualitative method to analyze the data. The primary data are taken from Charles Martin Smith's movies entitled Dolphin Tale (2011) and Dolphin Tale 2 (2014). In addition, the researcher used ecocriticism approach to analyze the positive and negative impacts of the human's behavior on the dolphin's life. Theories of human and nature and dolphin studies are also used to analyze the impacts of the human's behavior on the dolphin's life. The results show that some human behaviors can give negative impacts while some other give positive impacts to the dolphin's life. The negative impacts can be seen on the dolphin that gets injured because of human behavior. Meanwhile, the positive ones can be seen on the dolphin that is successfuly recovered. Based on those findings, it can be concluded that there should be a balance of human behaviors which affect the dolphin's life.
\end{abstract}

Keywords: Cinematography; Dolphin; Dolphin Tale; Ecocriticism; Human and Nature.

http://jos.unsoed.ac.id/index.php/ies

\section{INTRODUCTION}

The damages of the ecosystem balance are caused by two factors: natural and human factors. Natural factors are something that occur because of natura; activity without human interference. Meanwhile, human factors trigger damages that happen because of human intervention. Human existence has a close relation with the nature. They need natural resources to maintain their necessity in order to survive. In fact, every single part of human being is related to nature, even they live by the rules of nature (Schultz, 2002: 62). It means that human has a very strong bond with nature.

Human interacts with nature through various ways to find out that nature must be maintained properly in order to enable the future generation enjoy the beauty of life on earth. That is the real manifestation of human moral responsibility to nature. 
However, not all humans have a sense of responsibility in managing the nature. In fact, there are so many humans who often act as if they are separated from nature and assume as if they can live without nature (Schultz, 2002: 62). Human irresponsible behaviors in taking the natural resources cause several natural damages. The huge natural exploitation will give huge impacts to the ecosystem and the creatures that live there.

One of the creatures that is affected by such an irresponsible behavior is dolphin. Nowadays, there are many dolphin shows, and this means that human catch them to be trained to entertain the audience. William M. Johnson in his book A History of Animals in Entertainment explains that the dolphin show was first held in 1938 in Florida, United States. Since then, dolphin circuses have sprung up all over the world. The poor treatment of animals lead the activists to demand the closure of the dolphin show. Since the Marine Mammals Protection Act had been created in 1975 in the United States, dolphin performances have begun to close one by one. In England, 36 dolphin performances were closed in the 1970s for the next three decades. However, according to Pramudya Harzani, chairman of the Jakarta Animal Aid Network (JAAN), Indonesia has become the last country in the world to have a dolphin circus (tempo.co: 2012). Nowadays, the issue about dolphin circus that is for educational purposes or simply an act of exploitation remains a controversy among many circles.

In addition, boat activities on the sea also can affect dolphin's life. Mattson et al. (2005: 135) explicate that boats activity can give impacts both direct and indirect to dolphins. The dolphins may have severe injury if the boats bump into them. This condition makes many people put high concern on this case. They build the conservation center for dolphin and do some champaigns and socializations in order to raise people's awareness to protect them. Some people also raise the stories about the dolphin's life into a literary work such as novels, films, poems and many more. One of the literary works that clearly illustrates the impacts of human's behavior on dolphin's life is Dolphin Tale.

In 2011, a Californian director named Charles Martin Smith directed a movie entitled Dolphin Tale. This movie is based on a true story of Winter, a female dolphin from Florida that has severe injury on her tail. She was found by a boy named Sawyer in Mosquito Lagoon, near Cape Canaveral, Florida. She was trapped over the rope and crab's trap. The team from Clearwater Marine Aquarium (CMA) brought her to get the first aid. Her condition caused her tail got amputated in order to prevent some infections.

Then in 2014, Smith released a new movie entitled Dolphin Tale 2 as the next story of Dolphin Tale. The Dolphin Tale 2 tells about Winter and two others dolphins named Mandy and Hope that were succeessfully recovered. In addition, the second series also describes Winter's condition after losing her friend named Panama and how the CMA try to help Winter.

Since this research discusses about how human behaviors affect the dolphin's life, so this study employs the ecocriticism approach to analyze the issues in Dolphin Tale Series. According to Cheryll Glotfelty (1996: xviii), ecocriticism is the study of the relationship between literature and physical environment. Ecocriticism is an approach to study with environmental perspectives in literary work. It discusses literature with a natural-based approach. By broadening the scope and the realm, 
ecocriticism directs literary criticism into a social and public role by paying attention to the natural environment.

Since it discusses human and nature, there will be a discussion about the relationship between human and nature. The researcher also provides an explanation about dolphin study since the issue taken in this research is about dolphin.

Human and nature have close relationship because they need each other to survive. Human needs nature to survive and nature needs human to maintain and manage it. Human's survival depends on an ecological balance with nature (Schultz, 2002). If human and nature have a balance relationship, they will create mutually beneficial life to each other.

Among the thousands of members of the animal kingdom, dolphins take the top places regarding intelligence. Dolphin's brain is astonishingly complex and almost comparable to humans. The size of a dolphin cerebellum is significantly larger than human (Marino, et al., 2000: 209). The cerebellum itself has a function to involve the cognitive process of motoric control (Leiner et al., 1993, 1995; Fiez, 1996). Their brain is capable of understanding, reasoning, learning, and other cognitive processes. Kuczaj et al. (2012: 73) argue that dolphin emotional displays are expressed through a variety of modalities, including sound, postures, and touch. At a certain situation, they also can feel stress. Most of them experience stress if they live in captivity. The conditions of confinement might be stressful and harmful to dolphins (Carter, 1982: 193). The differences between the captivity and wild are the biggest problems for dolphin. They have to adapt with the new environment in order to survive.

Based on the above explanation, this research aims at figuring out the impacts of the human behaviors on the dolphin's life as illustrated in the movies entitled Dolphin Tale (2011) and Dolphin Tale 2 (2014) directed by Charles Martin Smith by employing the ecocriticism approach.

\section{RESEARCH METHOD}

This research is a descriptive qualitative research in which this research got the primary data from the movies entitled Dolphin Tale (2011) and Dolphin Tale 2 (2014) and the secondary data are taken from previous studies, journals, articles, or another possible internet sources. The data were collected by watching, rewatching, taking evidences, and reducing evidences. The researcher categorized them based on the issues of human behaviors which affect the dolphin's life both for the positive and negative impacts.

\section{RESULT AND DISCUSSION}

Dolphin Tale movie series show that human behaviors will bring positive and negative impacts on the dolphin's life. The negative impacts can be seen directly when the dolphins are injured because of human behavior. The lack sense of caring of the environment also leads to the decreasing of the environment quality. Dolphins nature habitat becomes endangered.

However, not all human create those bad things. There are also people who care for and dedicate themselves to protect the dolphins. For instance, they built coservation place like the Clearwater Marine Aquarium (CMA) to help the marine 
animals especially the dolphins, invited people to be more care, and raised the awareness of the environment. The research discusses three prominent points namely the injured dolphin, Winter's recovery and CMA's role in rescuing the dolphin.

\section{The Injured Dolphin}

The relationship between dolphins and humans can be fascinating and it can occur both in the wild and captivity. However, those interactions somehow bring impacts to the dolphin's life. Dolphin Tale movie series clearly shows how human's behavior can affect dolphin's life. It shows negative impacts when the human's actions and behavior cause the dolphin's injury. Meanwhile, positive impacts can be seen from the way people take care of the injured dolphin and try to heal them. This part discusses the injured dolphin in Dolphin Tale movie series.

The first dolphin that got injured was Winter. Her tail had to be amputated due to the severe injury caused by a fisherman's crab trap. Actually the fisherman knew that there were dolphins flock in the area where they put the crab trap, but they do not really care about it and keep putting the crab trap on the area. Their indifference about the environment can endanger the dolphin. This behavior leads to the negative impacts which affect dolphin's life. Their habitat was disrupted by the fishermen's boat activity and their crab trap. In this case, Winter's tail is trapped in the crab trap and it makes her tail severely injured.

Winter was found by an old man and he immediately contacted 911 . Then the CMA (Clearwater Marine Aquarium) came to rescue Winter by bring her to CMA and did some test to check her condition. Her injured tail should be amputated due to the severe injury. In fact, losing the tail for a dolphin is like the end of their life. They will no longer be able to swim freely as before. It means that they will spend the rest of their life in a captivity and depend their life on the human around them.

Fortunately, there was a prosthetic doctor named dr. McCarthy who wanted to help her. He made an artificial tail for Winter which was made from silicon. This is really a fascinating invention because he never makes a prosthetic tail for a dolphin before. The CMA team always make the best effort for Winter to save her life. Although she refused to wear the artificial tail several times, dr. McCarthy always tried to make the new tail with the best material which makes Winter could feel comfortable with it.

Based on the above discussion, it is clearly seen how human's behavior can impact dolphin's life both positive and negative. The negative impact is the result of human indifference, in this case is shown by the fishermen. The irresponsible behavior results in Winter's injury which makes her tail amputated. Losing the tail for dolphins is a nightmare because their tail is an important part which has the function to move their body. It would be hard to move especially when looking for food. In addition, Winter is unable to be released to the wild because she will find it difficult to look for food. While the positive impacts can be seen fromhow the people do their best effort to create a comfortable artificial tail for Winter. The artificial tail helps her to reduce the effect of the injury on her spinal cords. The spinal cord has a function to control breath, heartbeat, and movement. Her injury must be taken 
care of as soon as possible to save her life. Fortunately, the CMA team succeed to make an artificial tail and this gives hope for Winter to live longer.

The dolphin in CMA should pass several test such as blood work, gastrics and the other tests (depends on their injuries) before they are released to the wild. Since the dolphins in CMA get the foods provided only by human, they need to do the last test that is catching the living fish. This is done in order to test the dolphins' capability to nourish themselves. One of the dolphins that successfully passes all the tests is Mandy. She was found stranded on the beach with severe sunburn on her skin and other injuries. She was really frightened and shocked when the CMA team tried to rescue her. She moved very aggressively and makes the CMA team overwhelmed. Actually this is a very normal scene to happen because it is a form of defense mechanism when a dolphin feels threatened.

However, the team was succesful in evacuating and they brought her to CMA to get help. The CMA team gave her some treatments to heal her sunburn and injuries. Then, before the dolphins were released, they would undergo some test such as the blood test, gastrics, X-rays, and soon to make sure that they are okay to be released to the wild. Based on the following dialogue, dr. Clay explains about Mandy's test result:

Her blood work is all fine. Her gastrics are all fine. X-rays of her lungs, all negative. That's a good thing. There's no sign of infection, so we've discontinued antibiotics. White cell count is normal. And her sunburn is totally healed. (Dolphin Tale 2, $35: 20-35-50$ )

Mandy's case is the example of the dolphin that is successfuly recovered and then released back to the wild in Dolphin Tale 2. It clearly shows how humans behavior can give positive impacts on dolphin's life.

Another dolphin that gets injured was Krista. She needs to get some treatments due to her conditions after a collision with a boat. In fact, boat activity near dolphin flock is really dangerous. Gubbins (2002) states that boats pose both direct and indirect threats to dolphins. Boats activity can cause dolphins to change movement patterns, alter behavior, or even collide with other dolphins. Sawyer depicts Krista's condition as "[a]nd that's Krista. She was just run over by a boat. So when she heals, we can send her home" (Dolphin Tale, 38:58-39:02). This line shows that the reason of Krista being injured that is caused by the boat activity. This clearly shows the negative impacts of human's behavior towards dolphin' life. Some humans are so oblivious to the situations and conditions around them while riding the boat which give fatal impacts to the dolphins.

Another dolphin that lives in CMA is Panama. She is believed to be partly or fully deaf. She relies on boaters to give her fish or scraps because she could not catch fish on her own in the wild. For 12 years, Panama has brought joy to the hearts of thousands of visitors at CMA and has taught them the importance of marine wild conservation. When Winter came to CMA, Panama quickly adopted her as a surrogate daughter. Unfortunately, Panama died because of respiratory failure which is common for dolphin that is over 40 years. Panama is depicted before she dies as follows: 
That's Panama. She was rescued 12 years ago, unable to catch fish. And we found out why. It's actually because she's deaf, which makes her unable to echolocate. She's also very old for a dolphin. Over 40, we think." (Dolphin Tale 2, 07:22-07:34)

The quote above shows how the CMA team lets her live at captivity due to her conditions. According to Williamson (2018), the survival average of dolphins in captivity for all individuals who survived more than one year is 12 years, 9 months and 8 days. Panama was rescued in 2000, and she died in 2013 . Besides, she was too old for a dolphin which is possible for her to get infected by some diseases.

By saving Panama, CMA team helps her to live longer because she is deaf and unable to echolocate which means she cannot get the food by herself. Living in captivity becomes the best choice for Panama in order to help her get food. If she is released back to the wild it will endanger her life because she only gets food when the boaters give her fish or scraps. The risk of colliding with the boat is really high and it is really dangerous for her, therefore Panama has to spend the rest of her life in captivity. She dies after 12 years living in captivity.

However, living in captivity for dolphins is such a dilemma. The injured dolphins need to be placed at the captivity to get the first aid, but on the other side the risk of the death is high as well. The dolphin brought to the captivity needs to adapt with the new environment and also the new way to get foods. In captivity, the dolphins have limited space to swim and only get the food from human. For the dolphins that survive from their injury is not a big deal because they will be released back to the wild. However, for the dolphins like Winter and Panama that are disabled, it is not easy. They need the periodical check to make sure of their health conditions and also to prevent them from stress. If the dolphin get stress, it is really dangerous for them because it may result in degenerative psychological and physical changes. Nevertheless, although it is better for dolphin to live freely in the wild, somehow the dolphins need the captivity in terms of healing the injury. By healing the injury, the dolphins will live longer.

\section{Winter's Recovery}

The main character in Dolphin Tale movie series is Winter. She has severe injury on her tail which is why she cannot be released to the wild because she might get difficulties to survive. Her tail is amputated and she cannot swim normally like the other dolphins that swim by moving their tail up and down. Meanwhile, Winter swims by moving her tail from side to side. This swimming pattern causes the scoliosis on her spine, so she has to wear the artificial tail in order to reduce its effect. Fortunately a prosthetic doctor from the clinic for military amputees named Cameron McCarthy wants to help her. Before he comes to CMA to help Winter, he helps Kyle (Sawyer's brother) to heal due to a severe spinal injury during the military. Based on those situations, Sawyer meets and asks dr. McCarthy to help Winter.

The first time Sawyer meets Winter to release the rope and crab trap from her body, she looks scared of him because she feels that he may hurt her. This is because 
of her being that stranded and trapped in the rope and crab trap. Those are the biggest things that trigger her to feel scared and aware of the situation arround her.

Winter finds it difficult to adapt with the new environment in the captivity. At the time she arrives in CMA, she refuses the food from the trainer. According to Dima and Gache (2004: 413), this condition is called "the suicide". The suicide condition becomes one of the common reasons of the death of dolphins in captivity. In this condition, a dolphin usually refuses the food or strikes their body against the pool's walls until they die. It happens to Winter before Sawyer comes to CMA. She refuses the food from the trainer until Sawyer comes and tries to give her the foods (pedialyte; baby formula) patiently and lovingly. He also gives the sign that the food is not dangerous for her. Winter may be confused, frightened and feels unsafe which makes her refuse the food. After several trial, Sawyer earns Winter's trust. Then, Winter finally accepts the food.

CMA team starts to pay more attention to Winter after her tail being amputated because she has scoliosis on her spine due to the wrong swimming patterns. Giving her the artificial tail is the best decission to reduce the effects. However, putting the artificial tail to dolphin is another challenge. Winter may feel frightened and uncomfortable because of the artificial tail. It is proven when she always strikes the artificial tail into the pool's borders until it breaks.

Winter's refusal on her artificial tail makes the CMA team worry about her conditions because her scoliosis can get worse if it is not healed immediately. Dolphin's spinal cord is the same as human, it controls everything such as breath, heartbeat, and movement. If her scoliosis gets worse, it puts her into danger.

Although Winter always breaks the artificial tail, the CMA team, Sawyer and dr. McCarthy always try to make a new one for her and put it on Winter's tail. This makes her more stressed and frightened because she has to try it several times. Fortunately, Sawyer as the one who is really close to Winter can detect the cause of her restlessness, that is the sock on her tail. The sock is made of slightly rigid silicone which makes her difficult to swim. So they have to change the sock's material with the more comfortable one.

Just like a seatbelt, the function of the sock is to prevent the artificial tail to loose. Dr. McCarthy finally changes the sock's material with the softest silicone which is called "Winter Gel". Winter does not refuse to wear it because she feels comfortable with it. She can swim like a normal dolphin and the new tail will help her scoliosis to be healed. The special silicon gel sock developed for Winter is now making prosthetic more comfortable for human and animal amputees. It makes Sawyer and the other people satisfied with this improvement.

Winter and Sawyer are really close to each other. Sawyer even does not come to school only to meet Winter at CMA and play with her. They always spend time together and this creates a strong bond between them which makes them easily know each other feeling. The strong emotional bond between both dolphins and human makes them care for each other. This conditions makes Winter probably knows if Sawyer is sad or happy and vice versa.

When Winter is not in a good condition, Sawyer also tries to take care of her and show his affection to make Winter comfortable. Although they have strong connections, dolphin is still dolphin, an animal that has the wild side. Sometimes 
dolphins also become agressive if there is something that trigger them to do something they do not want to do.

Winter starts to be agressive to Sawyer before Panama dies. She always shows some signs to Sawyer and the other trainers. She always splashes the water to Sawyer as the sign that she refuses to swim with Panama. Winter wants them to know that Panama is not in a good condition, but Sawyer and the trainers do not realize the sign from her. It makes her keep showing the strange behavior to Sawyer and the trainers. It is also proven by the dialogue Sawyer and Phoebe (the trainer). Here are the dialogues when Winter is showing the signs to them :

Phoebe : "What's wrong with her?"

Sawyer: "I don't know. She's acting really strange."

Phoebe: "Panama is too. She didn't eat

her 2 p.m. bucket or her 5." (Dolphin Tale 2, 09:36-10:25)

The signs from Winter are true. The next day Panama's dead body is found at the bottom of the pool. After that, Winter's condition is getting worse. She always hides under the platform and does not want to play with Sawyer and the other trainers. She refuses to wear the artificial tail, even she hits Sawyer on the face until he falls into the pool and gets injury on his hand.

Such situations above are in line with what Dima and Gache (2004: 415) state that a very long isolation of dolphins brings out the appearance of apathy and total indifference when the animal hides under the nourishment bridge and refusing the food. After Panama is dead, Winter always hides under the platform. She may feel sad and lonely after losing her mother figure. Since dolphins in the natural habitat live with their flock, living alone without any friends can make them feel lonely, sad and stressed. Her behaviors become passive and she has the high level of cortisol. Cortisol is a hormone produced by the adrenaline gland that regulates stress response, blood pressure and sugar level. This conditions means that she is severely stressed. It is proven by the dialogue of George from USDA that "behavior's certainly off. I see the blood work shows elevated cortisol levels. Clay, this animal is severely stressed" (Dolphin Tale 2, 30:05-30:15).

Dolphins really need a friend because they are social animals. Just like human, dolphins also need to socialize, interact and comunicate with others to prevent stress in the captivity. Kuczaj et all. (2012: 73) state that dolphins live in dynamic social groups and it is likely that emotions play important roles in their social interactions. If dolphins live alone in the captivity, it can be said that they are isolated. Dolphins' isolation is a strong factor that triggers stress. It is also mentioned in the movie on the following dialogue of George from USDA:

It's a major violation for her to be isolated like this. You know that. She's stressed, she's isolated, her scoliosis is getting worse. That animal needs to be paired with another female, and soon (Dolphin Tale 2, 30:05-31:33). 
However, dr. Clay is also in difficult position. He has to decide to keep Mandy on the pool to accompany Winter or to release her to the wild because she is already healed and ready to be released. He does not want to keep Mandy in captivity for a longer time because he knows that dolphins need to live in the wild with their flock. After all, his mission to heal her is over and she deserves to be released. On the other side, if he releases Mandy to the wild it means Winter will live alone in captivity. After losing Panama, losing Mandy will make her more stressful.

Finally, dr. Clay decides to release Mandy to the wild after a lot of considerations. Winter lives alone in the captivity and her only friend is Sawyer. He always comes to the pool to accompany her and to play together, so Winter will not feel lonely anymore. However, Sawyer cannot stay with her for a long time because he has to go abroad to continue his study.

Fortunately, there is a female dolphin that comes to the CMA named Hope. Dr. Clay named her 'Hope' because she is a hope for Winter to heal her stress. She is still a baby and it is impossible to release her to the wild, so these conditions are perfect for them to live in one pool.

In fact, it is hard to pair them in one pool in the beginning. Hope always observes Winter's body, especially on her tail to make sure that she is not dangerous. She refuses her because she is affraid of Winter. Winter has no tail and a strange way of swimming. The first trial fails because hope shows her refusal by swimming agressively around the pool and it makes Winter scared of her.

The next trial, CMA team decides to put the artificial tail on Winter's body before putting them in one pool. Just like the previous one, in the beginning Hope observes Winter's body but now she does not show the refusal sign. She is not afraid anymore with Winter because the artificial tail helps her to swim like the normal dolphins. The result is that both of them accept each other to be friend and live together in one pool. It is proven by the dialogue from dr. Clay that "they're accepting. They're accepting!" (Dolphin Tale 2, 01:29:22-01:29:39)

There are many scenes show that Sawyer has a great role in Winter's recovery. Sawyer always spends his time to accompany Winter. He creates good interaction while playing together by talking to her and affectionately stroking Winter's body. It helps Winter that feel scare and lonely at the first time she arrives in CMA, when she stress on trying to wear the artificial tail and after losing her Mother figure, Panama. Both of them already have a strong connectedness.

According to Schultz (2002) the connectedness leads to caring, and this sense of caring will lead them to make a commitment to protect nature. Here, Sawyer really cares with the animals' condition in CMA especially Winter. He always gives the affection to her by swimming and playing with her. Winter seems to have no passion to live but after seeing Sawyer, she looks happy even the first time she produces the sound that is similar to tweety birds for him. Their interaction creates a very strong bond between them which makes Winter quickly heals. During the mourning time after Panama's death, Sawyer also tries to make her feel better. The CMA team also has the great efforts to find other dolphins to accompany Winter in the captivity. Then, Hope comes to them and just like her name, she becomes a hope for Winter to heal her from her stress. There are so many people who care for Winter. They feel happy after knowing that both Winter and Hope accept each other to live together in one pool. 
Since Winter has a new friend, it is expected that her conditions get better. Although the captivities are not good for dolphins to live in for a long time, somehow it becomes the best place for them to live longer instead of releasing them to the wild. If the CMA team releases Winter to the wild, it may be dangerous for her because other dolphins are unfamiliar with her swimming pattern and also her artificial tail. She also will be difficult to nourish herself because of her conditions. Although she wears the artificial tail, it still is impossible to release her to the wild because the CMA team needs to periodically check her tail. Therefore, the best choice for Winter is to live in captivity in order to make her live longer.

\section{CMA's Role in Rescuing The Dolphin}

The Dolphin Tale movie series takes place in Florida. There is a place used for helping the wounded marine animals called CMA (Clearwater Marine Aquarium). CMA itself is a non-profit organization and aquarium in Florida. This organization dedicates themselves to rescue, cure and release the sick and injured marine animals. In addition, this organization also uses as a public education, research and animal therapy.

In fact, this place does not only save the dolphin but also save the others marine animals, yet in this movie the focus is the dolphin. Their Motto is "Rescue, Rehab, Release" which means they rescue the injured or sick dolphin, then give them the treatments to heal them from the injury, and after the dolphin are totally healed the CMA team will release them to the wild as their real home.

The people in Dolphin Tale movie series are really concerned about dolphin. At one point, Winter needs the new artificial tail with a better material to make her comfortable while swimming. However, the poor financial condition of CMA almost make it impossible to continue running the center and all of the animals will be moved to the other place. That condition is getting worse after the storm damage at CMA. It requires a lot of money to clean it up again. However, with the great efforts, people try hard to maintain the existence of CMA in order to protect and save the marine animals, especially the dolphins. Here, dr. Clay insists on maintaining the existence of CMA, while others are desperate because of the financial conditions.

However, dr. Clay still convinces her that CMA can still operate. In order to keep the existence of CMA and make the new tail for Winter, Sawyer and the CMA team are doing campaigns to raise fund. This action is inspired by a mother who drives her car from Atlanta to Florida with her daughter in order to meet Winter. Her daughter has a disability on her leg and it makes them come to CMA to see Winter. It gives a motivation for her daughter so that she does not have to feel insecure and inferior about her condition.

Sawyer has faith that there are many people out there who have similar conditions to the girl from Atlanta. Meanwhile, his brother asked Sandra Sinclair (the news anchor) to tell the story about Winter's effort to still alive in order to raise the people's awarenes about this case. She broadcasted it on television and also the website. Those actions result the great responses from people. Sawyer and the CMA team also held a carnival to save CMA. The carnival proves to be a great success and raises a lot of money. 
Winter gets her new artificial tail with improved material. The CMA also changes significantly and becomes a proper place to animals who live there. It can be seen on the condition of the CMA in Dolphin Tale 2. The place looks better with great buildings, facilities and services. Many people come to that place not only to see Winter and the others animals but also for the humanity and educational purposes. From the real footage of Dolphin Tale, it shows that many people with disability come to CMA to see Winter. It is because Winter's story is really inspiring for those who have the same condition like her. It gives disabled people motivation to keep the morale and confidence about their conditions.

The CMA has the great role in rescuing the wounded animals, especially dolphin. By saving the wounded dolphins and then release them to the wild, it give positives impacts to the dolphin's life and also the environment. It will save their lives and also maintain their population. If their population decreases, of course it will have a negative impact on nature. Dolphins are important to the ecosystems because they are the apex of marine predator which control the populations of the animals they prey on such as fishes and squid (Dolphin-World, 2013). Without dolphins, the amount of the animals they prey on would increase and this would disrupt the natural balance in the food chain and could negatively affect other wild and the health of the marine environment. Releasing dolphins to the wild also prevents them from isolation, because healthy animals deserve to live freely in real their habitat.

\section{CONCLUSION}

Human behaviors both positive and negative can affect the nature conditions. In negative sides, the impact can be seen from the dolphin that gets injured because of human indifference. The other case is the human oblivious to the situations and conditions around them while riding the boat which gives the fatal impact on dolphin. Meanwhile, the positive impact can be seen from the dolphin that is successfully recovered. The CMA team rescues the injured dolphin and gives some treatments to heal them. After they are successfully recovered, they will be released back to the wild. By saving the wounded dolphins and then release them to the wild, it will give the positives impact to dolphin's life and also the environment. It will save their life and also maintain their population.

However, not all dolphins are successfully released to the wild. There are some dolphins who stay at CMA (captivity) for the rest of their life because their conditions make them unable to live in the wild. If the CMA team released those dolphins to the wild, it will endanger their life. So living in the captivity becomes the best choice to make the dolphins live longer. Saving the dolphin's life will give the positive impacts to the environment. It will maintain their population because they are the apex of marine predator which controls the populations of the animals they prey on.

In conclusion, using ecocriticism to examine human feelings, views, experiences, and behavior towards the environment in literary works can be a means to lead human practices in maintaining the environment. Some of human behavior may have negative impact on the nature especially the dolphin's life, but the others still have concern about dolphin survival in order to maintain their population. 


\section{REFERENCES}

Carter, Nick. (1982). "Effects of Psycho Physiological Stress on Captive Dolphins." International Journal for the Study of Animal Problems" 3(3), 193-198.

Dima, Ligia Dorina \& Gache, Carmen. (2004). “Dolphins in Captivity: Realities and Perspectives". 413-417.

Fiez, J.A. (1996). Cerebellar contributions to cognition. Neuron, 16: 13-15.

Glotfelty, Cheryll (1996) "Introduction: Literary Studies in an Age of Environmental Crisis" In Cheryll Glotfelty and Harold Fromm, (eds.) The Ecocriticism Reader: Landmarks in Literary Ecology, xviii. The University of Georgia Press Athens, Georgia 30602.

Gubbins, C. M. (2002). "Association patterns of resident bottlenose dolphins (Tursiops truncatus) in a South Carolina estuary". Aquatic Mammals, 28(1), 24-31.

Kuczaj, Stan. Highfill, Lauren E. Makecha, Radhika. Eskelinen, Holli. (2012). "Why Do Dolphin Smile? A Comparative Perspective on Dolphin Emotions and Emotional Expressions". Emotions of Animals and Humans : Comparative Perspective. The Science of The Mind. 73-74.

Leiner, H.C., A.L. Leiner, and R.S. Dow. (1993). Cognitive and language functions of The human cerebellum. Trends Neurosci., 16: 444-447.

Leiner, H.C., A.L. Leiner, and R.S. Dow. (1995). The underestimated cerebellum. Human Brain Mapping, 2: 244-254.

Marino, Lori. Rilling , James K. Lin, Shinko K. Ridgway, Sam H. (2000). "Relative Volume of the Cerebellum in Dolphins and Comparison with Anthropoid Primate". Brain Behavior and Evolution, 209. DOI: $10.1159 / 000047205$.

Mattson, Megan Cope. Jeanette A. Thomas. David St. Aubin. (2005). "Effects of Boat Activity on the Behavior of Bottlenose Dolphins (Tursiops truncatus) in Waters Surrounding Hilton Head Island, South Carolina". Aquatic Mammals 2005, 31(1), 133-140, DOI 10.1578/AM.31.1.2005.133.

Schultz, P.W. (2002). "Inclusion with nature. In P. Schmuck and W.P. Schultz (eds.)” Psychology of Sustainable Development, 61-95. Boston: Kluwer Academic Publishers.

Smith, Charles. M. (Director). (2011). “Dolphin Tale”. Alcon Entertainment, Warner 
135 J-Lalite: Journal of English Studies Vol.1, No.2, December, 2020

Bros. Picture. Clearwater, Florida, United States. 113 minutes.

Smith, Charles. M. (Director). (2014). “Dolphin Tale 2”. Alcon Entertainment, Warner Bros. Picture. United States. 107 minutes.

Tempo.co (2012). "Indonesia, Negara Terakhir Sirkus Lumba-lumba”. Tempo.co. https://tekno.tempo.co/read/430386/indonesia-negara-terakhir-sirkus lumbalumba/full\&view=ok/. On February $18^{\text {th }} 2019$.

Williamson, Cathy (2018) "How Long do Bottlenose Dolphins Survive in Captivity?”. Whale and Dolphin Conservation. https://us.whales.org/2018/08/23-howlong-do-bottlenose-dolphins-survive-in-captivity/. On October $7^{\text {th }} 2019$. 